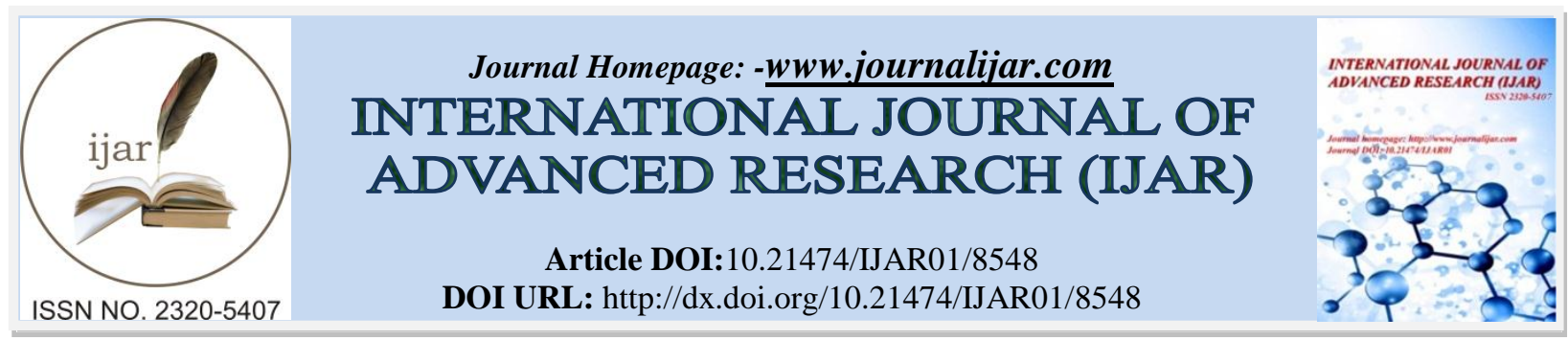

RESEARCH ARTICLE

\title{
EFFECT OF LASER PHOTOCOAGULATION ON CONTRAST SENSITIVITY, VISUAL ACUITY AND COLOUR VISION IN PATIENTS OF DIABETIC MACULAR EDEMA.
}

\author{
Nirmala Jyothi Pamu ${ }^{1}$, V. Rajeswara Rao ${ }^{2}$ and Chandana Priyanka $S^{3}$. \\ 1. Associate Professor, Department of Ophthalmology, AMC, Vishakhapatnam. Andhra Pradesh, INDIA. \\ 2. Professor, Department of Ophthalmology, AMC, Vishakhapatnam Andhra Pradesh, INDIA. \\ 3. Postgraduate, Department of Ophthalmology, AMC, Vishakhapatnam Andhra Pradesh, INDIA.
}

\section{Manuscript Info}

Manuscript History

Received: 11 December 2018

Final Accepted: 13 January 2019

Published: February 2019

\begin{abstract}
Aim: To assess the effects of laser photocoagulation on contrast sensitivity, visual acuity and colour vision in patients of diabetic macular edema.

Methods: It is a hospital-based prospective analytical study conducted on 30 eyes of type 1 and types 2 of diabetes mellitus patients with NPDR and non-centre involved diabetic macular edema of more than 18 years of age of both the sexes for a one-year duration.

Results: The majority belonged to the age group of 51-60 yrs. Males represented $60 \%$ with a peak incidence at 51-60 years and females represented $40 \%$. BCVA was stabilized in $63 \%$, improved by $26 \%$ and decreased by $10 \%$. In this study, the mean baseline contrast sensitivity was $0.49 \log$ CS which improved significantly to o.60 $\log$ CS and 0.64 $\operatorname{logs} \mathrm{CS}$ at 3 and 6 months respectively.No change in colour vision was noted at 6 months follow up

Conclusion: Timely treatment of Diabetic macular edema with laser retinal photocoagulation prevents further dysfunction and salvages involved retina causing statistically significant improvement in vision and quality of life.
\end{abstract}

Copy Right, IJAR, 2019, All rights reserved.

\section{Introduction:-}

Diabetes is a major global burden nowadays Diabetes mellitus is a group of metabolic diseases characterized by hyperglycemia resulting from defects in insulin secretion and insulin action or both. Chronic hyperglycemia is associated with damage to different organs especially to eyes kidneys and nerves heart and blood vessels. The prevalence of diabetes is increasing globally and is anticipated to rise from $4 \%$ in 1995 to $5.4 \%$ in $2020^{1}$. So the prevalence of its complications is also increasing globally. As per the World health organization, India has 31.7 million diabetic subjects ${ }^{2}$. Macular edema is the most common cause of moderate visual loss which occurs as a complication of diabetes ${ }^{3}$. Moderate visual loss is defined by ETDRS as a doubling of the visual angle that is a drop of 3 or more lines of Snellen's chart. The ETDRS demonstrated that focal laser photocoagulation reduces the risk of moderate visual loss in CSME. ${ }^{4}$

As the macula is concerned with visual acuity, colour vision, contrast sensitivity and form vision, the disease of the macula is associated with defective form vision, colour vision and contrast sensitivity. The changes in the contrast

Corresponding Author:-Nirmala Jyothi Pamu.

Address:-Associate Professor, Department of Ophthalmology, AMC, Vishakhapatnam. Andhra Pradesh, INDIA. 
sensitivity are present I the diabetics even with normal visual acuity recorded by the Snellen's chart. Mechanism of loss of contrast sensitivity in DME(diabetic macular edema) is not known but may be due to accumulation of abnormal fluids in the macula ${ }^{5,9}$ and enlargement of foveal avascular zone ${ }^{10}$ macular edema, is the thickening of retina in the region of macula caused by break down of inner retinal barrier at the papillary endothelial level. The prevalence of macular edema is more in non-insulin dependent diabetes mellitus patients requiring insulin for glycemic control ${ }^{6}$. The diabetic macular edema is broadly divided into focal macular edema and diffuse macular edema.

Optical coherence tomography (OCT) provides insight into underlying retinal layers and yields usual information. According to OCT, there are 5 distinct patterns of macular edema. (11)

1. Sponge-like retinal thickening

2. Cystoids macular edema

3. Subserous retinal detachment

4. Focal tractional retinal detachment

5. Taut posterior hyaloid membrane

According to current ETDRS guild lines, focal or grid laser photocoagulation remains the gold standard for diabetic macular edema without central involvement. EDTRS gave the treatment strategies' for diabetic macular edema and is followed worldwide. The central macular thickness was found to be the most predictive factor for visual prognosis. According to ETDRS Diabetic macular edema is can be graded into CSME which is a good indicator of laser photocoagulation. It includes any of the following findings:-

1. Retinal thickening at or within 500 microns of the centre of the macula

2. Hard exudates at or within $\mathbf{5 0 0}$ microns of the centre of the macula with the adjacent retinal thickening

3. An area or areas of retinal thickening at least disk area in size part of which is within one disc diameter of the centre of the macula

OCT definition retinal thickening due to DME $>2$ SD beyond the normal value outside the central subfield but $<$ mean + SD in spectral domain OCT within the central subfield. All through the central macular thickness was found to be most predictive factor additional factors like angiographic leakage at the inner subfields' also contribute to loss of visual acuity(VA).

In this study, we compared the changes in the VA, macular thickness and volume parameters measured with OCT in patients with non-central-involved macular edema (Non-CME) treated with focal laser photocoagulation.

\section{Aims and Objectives:-}

To evaluate visual acuity, colour vision, and contrast sensitivity in patients with non-centre involved diabetic macular edema following laser photocoagulation.

\section{Materials and Methods:-}

It is a hospital-based prospective analytical study conducted on 30 eyes of type 1 and type 2 of diabetes mellitus patients with NPDR and non-centre involved diabetic macular edema of more than 18 years of age of both the sexes. Definite retinal thickening due to diabetic macular edema within 3000 microns of the centre of macula but involving the central subfield.

According to DR CR. NET approved spectral domain OCT machine -ZEISS, cirrus < 290 in women and <305 in men. Patients with media not clear, active proliferative diabetic retinopathy and those who had undergone prior photocoagulation and patients with a history of recent ocular surgery, a patient with other disorders of retina / optic nerve In which contrast sensitivity is already compromised and best corrected visual acuity less than $3 / 60$ were excluded from the study

Visual acuity was recorded with the help of self-illuminated Snellen acuity chart placed at a distance of 6 meters and best corrected visual acuity (BCVA) taken after giving appropriate spherical and cylindrical lenses. These BCVA measurements are converted into log mar units for statistical analysis. 
Then the contrast sensitivity test was conducted by using Pelli Robison chart, which is a wall mount chart kept at a distance of 1 meter which is illuminated by room light. A contrast sensitivity test was conducted before the dilatation of the pupils.

Colour vision was recorded by using FARNS WORTH D12 test then detailed anterior segment evaluation was done by slit lamp examination and ocular comorbidities were ruled out.

The fundus evaluation was done with the help of direct and indirect ophthalmoscope. Then OCT was performed through dilated pupils using cirrus ziess HD-OCT macular scans

After fundus fluorescein angiography to detect the areas of the leak, laser photocoagulation was done by a single retina specialist in the retina clinic after obtaining written consent from the patient.

\section{Focal direct laser treatment:-}

Directly treat all leaking microaneurysms in areas of retinal thickening between 500 and $3000 \mu \mathrm{m}$ from the centre of the macula (but not within $500 \mu \mathrm{m}$ of the disc). -Spot size $-50 \mu \mathrm{m}$ - Burn duration -0.05 to $0.1 \mathrm{sec}$-power 50150 mwatt.

Modified grid laser: focal treatment for leaking microaneurysms and grid treatment to the areas of retinal thickening with diffuse leakage located more than 500 microns from the centre of the macula and 500 microns from the temporal margin of the optic disc. Spot size should be100 to 200 microns, duration of laser 0.10 second power-100$150 \mathrm{mWatt}$.

\section{Results:-}

The age groups of the patients included under the study ranged from 40-75 years with a mean age of 58.48 \pm 7.8years.

Figure 1:-

\begin{tabular}{|l|l|l|l|}
\hline Age group & Males & Females & Total \\
\hline $41-50$ & 3 & 5 & 8 \\
\hline $51-60$ & 9 & 5 & 14 \\
\hline $61-70$ & 5 & 2 & 7 \\
\hline $71-80$ & 1 & - & 1 \\
\hline Total & 18 & 12 & 30 \\
\hline
\end{tabular}

Figure 2:-

\begin{tabular}{|l|l|}
\hline Duration of diabetes & No. of eyes \\
\hline $0-5$ yrs & $\mathbf{1 0}$ \\
\hline $6-10$ yrs & $\mathbf{1 2}$ \\
\hline $11-15$ yrs & 4 \\
\hline $21-20$ yrs & 3 \\
\hline Total & 1 \\
\hline
\end{tabular}

Figure 3: 


\begin{tabular}{|l|l|}
\hline MILD NPDR & - \\
\hline MODERATE NPDR & 21 \\
\hline SEVERE NPDR & 9 \\
\hline Total & 30 \\
\hline
\end{tabular}

Figure 4:-

\begin{tabular}{|l|l|l|l|l|l|}
\hline Visit & $\begin{array}{l}\text { VISUAL } \\
\text { ACUITY }\end{array}$ & $\begin{array}{l}\text { CONTRAST } \\
\text { SENSITIVITY }\end{array}$ & MEAN CST & IZT & OZT \\
\hline Baseline & 0.35 & $0.49 \log \mathrm{cs}$ & 251.8 & 354.52 & 308.02 \\
\hline month & 0.34 & $0.60 \log \mathrm{cs}$ & 245.44 & 337.57 & 295.25 \\
\hline 6 month & 0.33 & $0.64 \log \mathrm{cs}$ & 243.20 & 334.33 & 292.14 \\
\hline
\end{tabular}

Figure 5:-

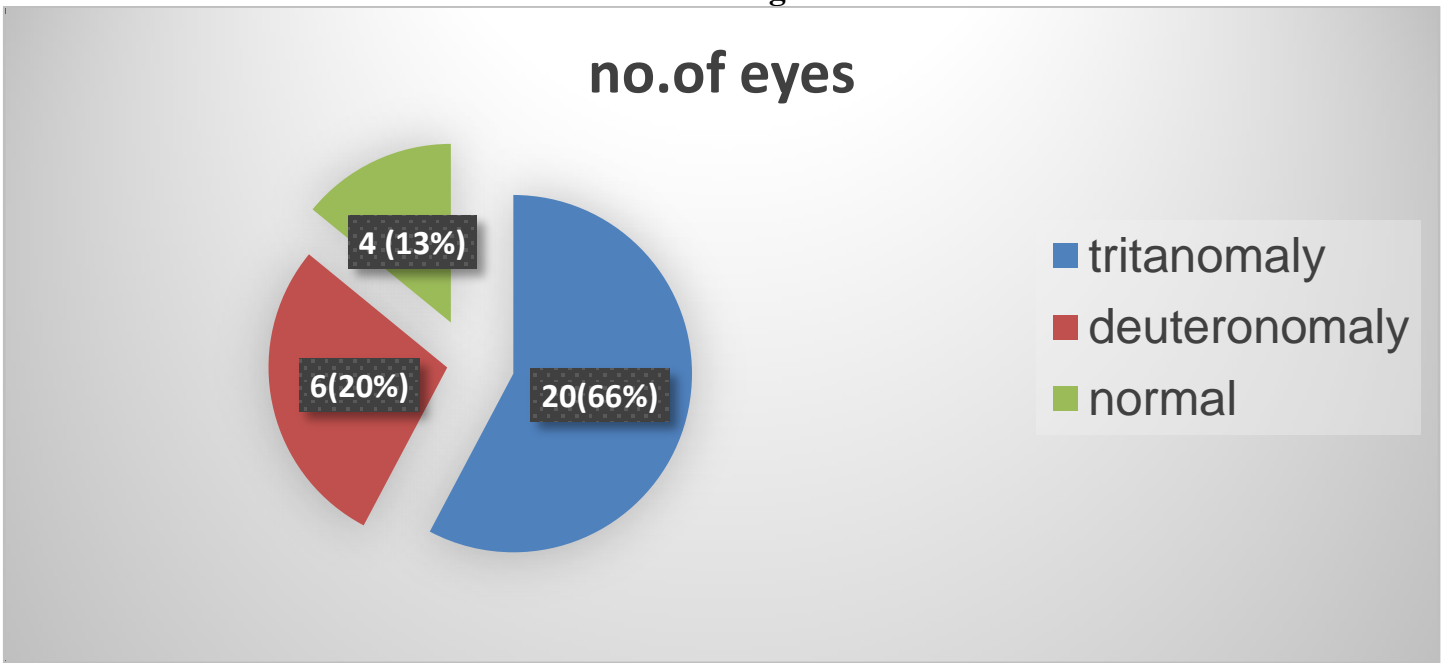

\section{Figure 6:-}

\begin{tabular}{|l|l|}
\hline BCVA & \\
\hline Improved & 8 \\
\hline Stable & 19 \\
\hline Decreased & 3 \\
\hline No. of eyes & 30 \\
\hline
\end{tabular}

\section{Discussion:-}

In the present study age group of the patients included under the study ranged from 41-75 years. The majority belonged to the age group of 51-60 yrs. This is in concordance with Seo and Park et al. ${ }^{12}$ study which showed the mean age of $57.9 \pm 13.8$ years. It was also in concordance with Arevalo et al. study with a mean age of $59.7 \pm 9.3$ years.

In the present study, males represented 60\% with a peak incidence at 51-60 years and females represented $40 \%$. A similar male preponderance was documented in Nagasawa $\mathrm{T}$ et al, Arevalo et al ${ }^{20}$, Ozkiris A et al ${ }^{15}$ which showed male to female ratio of $1.7: 1,1.2: 1,1.3: 1$ respectively. In a study conducted by Lee CM, and Olk RJ ${ }^{13}$ on modified grid laser photocoagulation in patients with diffuse diabetic macular oedema between the years 1981 and 1990 visual acuity improved in $14.5 \%$, unchanged in $60.9 \%$, and worse in $24.6 \%$ after treatment.

In our study, BCVA was stabilized in $63 \%$, improved by $26 \%$ and decreased by $10 \%$.In a study conducted by Talwar Det $\mathrm{al}^{14}$ on contrast sensitivity following laser photocoagulation in CSME, the mean pre-laser contrast sensitivity score was $121.3 \pm 83.6$ which increased significantly to a mean of $151.6 \pm 80.5$ which concluded that focal argon laser photocoagulation in CSME helps in improving the contrast sensitivity and stabilizes the visual acuity. In 
our study, the mean baseline contrast sensitivity was $0.49 \log$ CS which improved significantly to $0.60 \log$ CS and $0.64 \operatorname{logs} \mathrm{CS}$ at 3 and 6 months respectively.

In the present study Tritan defect was seen in 20 eyes (66\%), deutan defect seen in 6 eyes(20\%) and colour vision was normal in 4 eyes $(6 \%)$. No change in colour vision was noted at 6 months follow up. Sadiqulla et a ${ }^{16}$ reported a $^{17}$ red- green loss pattern prevailing then total colour blindness, Shin et al ${ }^{17}$ reported a blue-yellow loss pattern, the same reported by Patzetal ${ }^{18}$ andMa' ar et $\mathrm{al}^{19}$.

Limitations of the study are Limited duration of follow up, Long term complications of laser photocoagulation were unknown. Small sample size

\section{Conclusion:-}

Timely treatment of Diabetic macular oedema with laser retinal photocoagulation prevents further dysfunction and salvages involved retina causing statistically significant improvement in vision and quality of life.

\section{References:-}

1. King H, Aubert RE, Herman WH. Global burden of diabetes, 1995-2025: prevalence, numerical estimates, and projections. Diabetes Care 1998;21:1414-31

2. . Wild S, Roglic G, Green A. Global prevalence of diabetes, estimates for the year 2000 and projections for 2030. Diabetes Care 2004;27:1047-53.

3. Klein R, Barbara EKK, MossSE, Davis DM, DeMets DL. The Wisconsin Epidemiologic study of diabetic retinopathy 1V.Diabetic macular edema.Ophthalmology 1984;91:1464-74

4. Early Treatment Diabetic Retinopathy Study Research Group.Treatment techniques and clinical guidelines for photocoagulation of diabetic macular oedema: Early Treatment Diabetic Retinopathy Study.Report Number 2.Ophthalmology 1987;84:761-74

5. Bresnick GH. Diabetic maculopathy: a critical review highlighting diffuse macular edema. Ophthalmology. 1983; 90 : 1301 $-1317$

6. Dosso AA, Bonvin ER, Morel Y. Risk factors associated with contrast sensitivity loss in diabetic patients. Graefe's Arch Clin Exp Ophthalmol. 1996; 234: 300 - 305.

7. Ghafour IM, Foulds WS, Allan D. Contrast sensitivity in diabetic subjects with and without retinopathy. Br J Ophthalmol. 1982; 66: $492-495$.

8. Sala SD, Bertoni G, Somazzi L. Impaired contrast sensitivity with and without retinopathy: a new technique for rapid assessment. Br J Ophthalmol. 1985; 69: 136 - 142.

9. Hellstedt T, Kaaja R, Teramo K. Contrast sensitivity in diabetic pregnancy. Graefe's Arch Clin Exp Ophthalmol. 1997; 235: $70-75$.

10. Arend O, Remky A, Evans D. Contrast sensitivity loss is coupled with capillary dropout in patients with diabetes. Invest Ophthalmol Vis Sci. 1997; 38: 1819 - 1824.

11. Vishali Gupta, Amod Gupta, Mangat R Dogra. Atlas Optical Coherence Tomography of Macular Diseases.2004;22.

12. Seo JW, Park IW. Intravitreal bevacizumab for the treatment of diabetic macular edema. Korean journal of Ophthalmology. 2009 Mar 1;23(1):17-22.

13. Olk RJ. Modified grid argon (blue-green) laser photocoagulation for diffuse diabetic macular edema. Ophthalmology. 1986 Jul 1;93(7):938-50.

14. Talwar D, Sharma N, Pai A, Azad RV, Kohli A, Virdi PS. Contrast sensitivity following focal laser photocoagulation in clinically significant macular oedema due to diabetic retinopathy. Clinical \& experimental ophthalmology. 2001 Feb;29(1):17-21.

15. Özkiris A, Evereklioglu C, Erkilic K, Tamcelik N, Mirza E. Intravitreal triamcinolone acetonide injection as a primary treatment for diabetic macular edema. European journal of ophthalmology. 2004 Nov;14(6):543-9.

16. Sadiqulla M, Khan IA, Rahmath AG. OCT determined macular thickness in diabetic retinopathy and relation to colour vision deficiency patterns. International Journal of Medical Science and Public Health. 2014 Mar 1;3(3):265-9.

17. Shin YJ, Park KH, Hwang J-M, Wee W, Lee J, Lee I, Hyon J. A novel colour vision test for detection of diabetic macular edema. Invest Ophthalmol Vis Sci. 2014; 55:25-32. DOI:10.1167/iovs.13- 11698.

18. Patz A, Schatz H, Berkov J. Macular edema: an overlooked complication of diabetic retinopathy. Trans Am Acad Ophthalmol Otolaryngol. 1973; 77: 34-42.

19. Ma'ar N, Tittl M, Stur M, Reitner A. A new colour vision arrangement test to detect functional changes in diabetic macular oedema. Br J Ophthalmol. 2001; 85:47-51.

20. Arevalo JF, Fromow-Guerra J, Quiroz-Mercado H, Sanchez JG, Wu L, Maia M et al Pan-American Collaborative Retina Study Group. Primary intravitreal bevacizumab (Avastin) for diabetic macular edema: results from the Pan-American Collaborative Retina Study Group at 6-month follow-up. Ophthalmology. 2007;114:743-50. 